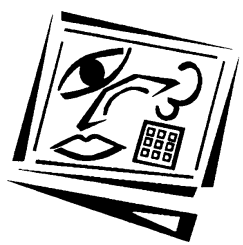

\title{
WebCT and online tutorials: New possibilities for student interaction
}

\author{
Jennifer Curtin \\ Monash University \\ Computer mediated communications technologies are being recommended \\ increasingly within the university environment as a means to enhance \\ flexible delivery and student learning. This paper presents my trial use of \\ the bulletin board within WebCT as a tutorial environment in which to \\ discuss prescribed readings. I investigate whether a computer based \\ tutorial setting can be used as a tool for learning, in addition to being a tool \\ for delivery of information. Specifically, I examine whether online tutorials \\ can be used to encourage students to undertake the readings, distinguish \\ the evidence and arguments of these, and relate the ideas to everyday \\ experience through a discussion with their peers, in an online environment.
}

\section{Introduction}

It seems that higher education institutions increasingly are looking to provide courses or parts thereof, online. The Commonwealth Department of Education, Training and Youth Affairs conducted research into the effectiveness of online education and the extent to which it is being undertaken by universities around Australia (Weekend Australian, 18-19 August, 2001). Within a number of universities staff are being encouraged to utilise alternative and flexible delivery methods, including WebCT. Through end of semester evaluations administered by Centre for the Enhancement of Learning, Teaching and Scholarship, students at the University of Canberra expressed desires to have online access to lecture notes, readings and a bulletin board. A bulletin board would encourage class discussion, enable posing of further questions about the readings and lectures, and provide for posting other messages and issues, allowing replies and responses from students.

I began to use WebCT in two undergraduate classes in 2000, primarily for posting lecture notes and tutorial questions. In their end of semester 
evaluations, a small proportion of the students stated a desire for an online bulletin board to encourage class discussion and pose further questions about the readings and lectures. So I began to think about how I might utilise the bulletin board facility that is available within WebCT in a way that would be pedagogically valuable for students. It seemed as if the students who identified the bulletin board as a potential discussion forum may have been searching for more opportunities to interact with other students.

Traditionally, tutorials are the place where students are given the opportunity to articulate their ideas and thoughts about issues and problems arising from the prescribed readings. Teaching in small groups such as tutorials "provides an opportunity for the interplay of ideas and views" (Adams, 1994, p. 1). Tutorials are an environment where there can be much more emphasis on student activity rather than on passive learning. Such activity is one of the ways for students to strive for higher order goals of "analysis, synthesis and understanding" which are representative of deep learning (Gibbs, 1992, p. 67).

Based on the study of a new policy on technology and teaching at Griffith University, Laurillard and Margetson (1997) maintain that communicating information through electronic means may not lead to an increased quality of learning. However, they argue it is possible that computer mediated communications technologies can lead to increased interactivity between students and between student and teacher (1997, p. 2; see also McMurray and Dunlop, 2000). This article presents my trial use of the bulletin board within WebCT, as a tutorial environment in which to discuss set readings. I was interested in whether a computer based tutorial setting could be used as a tool for learning, in addition to being a tool for delivery of information. Specifically, I wanted to investigate whether online tutorials could encourage students to undertake the readings (where the theoretical ideas were housed), distinguish the evidence and arguments of these, and relate the ideas to everyday experience through a discussion with their peers, in an online environment. These are features of a deep approach to learning as identified by Gibbs (1992) and Entwistle and Marton (cited in Ramsden, 1992, p. 46).

This paper is organised into four main sections. The first critically reviews the literature dealing with technology and online teaching and learning, with a focus on the problems and possibilities of the bulletin board. The second section outlines the actions I took in designing and implementing an online tutorial for my students in the unit Gender and Organisations, presented at the University of Canberra. In the third section I evaluate the 
extent to which bulletin boards allowed for student-student communication of ideas, opinions and issues around the prescribed readings. I then conclude with some reflections on my future use of the online mode for tutorials. I do not make any direct comparison in my study with traditional tutorial settings, so my conclusions are limited to the online environment.

\section{Bulletin boards: Perspectives on use for tutorials}

Although online environments have been around for more than a decade, the practice of online teaching and the use of bulletin boards as a teaching tool have created much interest in recent years, and the research into the pedagogical issues surrounding this mode of delivery reflects this. By linking what literature is available with earlier research on small group and active learning, it becomes possible to identify the potential strengths and weaknesses of the bulletin board environment.

One objective of small group teaching such as in tutorials is to promote deep learning through activities, by encouraging students to contribute their ideas and thoughts on the application of theory in practice, ask questions and formulate arguments (Ramsden, 1992, p. 14). But there are many factors that inhibit such participation. For example, teachers may spend too much time explaining rather than allowing students to do the articulating, thereby maintaining a strong element of teacher control (Powell, 1981). The possibility for articulation through discussion has also been reduced by time and size constraints that now exist in many universities. These factors are likely to reduce the opportunity for all students to participate fully in discussions.

Laurillard (1993) argued that computer mediated tutorials can benefit student learning, in that they offer students the opportunity of more time for input vis-a-vis teacher input, thereby enhancing the possibility for increased articulation and activity by students (see also Reeves, Laffey and Marlino, 1997).

Technology alone will not solve the problem of teacher control over the discussion process. "Networked computers can provide vehicles for learning materials and interaction but students still need the 'champions' who make the learning come alive - the e-moderators" (Salmon, 2000: p.11). Therefore, the moderation or facilitation process undertaken by the 
teacher is as important in the bulletin board environment as it is in the traditional tutorial environment. What is at issue is the extent to which students can take control of the learning process within the bulletin board environment (Forsyth, 1996; O'Sullivan and Miron, 2000). In addition, Forsyth suggests that some teachers may find new technology a threat because it reduces their control, challenging their place as the primary source of knowledge (Forsyth, 1996, p. 17). Shifting the locus of control could occur through students themselves taking up the role of moderator, potentially a useful learning activity in itself.

Thus it becomes important to reflect on the manner in which the engagement of students "re-positions the teacher's role from that of the authority figure ... to one of facilitator, ... reinforcing the importance of peer interaction for cognitive development" (McMurray and Dunlop, 2000). A range of techniques has been put forward in the literature to help facilitation online in a way that encourages peer interaction (Berge, 1995; Salmon, 2000). These include having clear objectives so that students know their time online is well spent, encouraging participation by asking questions that probe without making judgement, not expecting too much, developing activities that relate to student experiences, linking conversations together and encouraging students to ask questions of each other. Effective facilitation online also requires an understanding of the issues that are particular to an online environment, such as etiquette, technical skills, and how to create a sense of community amongst students online (Salmon, 2000; Phillips, 1999).

Discussion in traditional tutorials is often spontaneous and free flowing. This means that for students to participate, they have to respond almost immediately; it is a synchronous forum. This format may suit many students, but it could be interpreted as somewhat biased towards those who are confident about speaking in public, who are able to think on their feet (Kearsley, 1998; Merron, 1999). Reflecting on my use of traditional tutorial environments, spontaneous responses can be difficult for those for whom English is not a first language, for those from a non-English speaking background or for those who come from a minority culture." For some students then, the opportunity to participate may be lost if the pace of the discussion moves too quickly. This can be compared to computer mediated tutorials, when they are asynchronous, where the 'moment' to participate is drawn out. The use of bulletin boards then could provide a learning environment that permits a self paced engagement with the content (Laurillard in Ramsden, 1992, p. 159). 
Several studies of student responses to interaction online suggest students find it useful to see questions and responses from other students, as this helps them to gauge where the broad standard should be in relation to others. Students also like the fact that there is a record of the dialogue that can be used for further thought and study (Jones, 1999; McMurray and Dunlop, 2000). However, there is not yet enough research to indicate that online interaction guarantees student centred learning (MacKnight, 1996; Saltmarsh, 2000). For example, Sherry (1998) claims that on average one third will seldom participate in online learning activities and, unless it is assessed, apathy can take over, although this is not isolated to the online environment.

Attendance is an important aspect to the tutorial environment, for if students do not attend, the opportunity for meaningful communication between students is significantly reduced (Laurillard, 1993). An increasing number of students are in full time jobs, studying part time, or are full time students working part time. Finding tutorial times to fit with student schedules can be a difficult task. In this scenario, supplementing seminar sessions with an online tutorial may facilitate student attendance (as a necessary precursor to inclusive participation), with students able to login from anywhere, anytime and for however long as suits them. ${ }^{i i}$ It is this flexibility that has been identified as one of the major advantages of the online teaching forum (Ramsden, 1992; Saltmarsh, 2000). So it is necessary to ensure that all students have access to the online environment, and that logging on and making postings are relatively easy, thereby allowing students to focus on the task with limited anxiety (Berge, 1995; Salmon, 2000).

Online tutorials are not without criticism (Ramsden, 1992; Salmon, 2000). Sometimes students may feel nervous about putting their ideas 'out there' in a written form, whereby they become extremely public (Merron, 1999). Verbal comments are public in traditional tutorials only for a moment. However, the obverse of this is that because students cannot see each other, there is "a protective ignorance surrounding a person's social roles, rank and status" (Merron, 1999). While this degree of anonymity may have its advantages for those who might be less confident about speaking in a traditional tutorial, it may also have its disadvantages. In an analysis of the democratic aspects of using web based technology in teaching cultural diversity, Reid argues that anonymity can provide an opportunity for students to express resentment in a way that could be confronting for 
other students, particularly around issues of race, ethnicity, or sex (Reid, 1999).

There is also a suggestion that online teaching undermines the development of oral communication skills, and the creation of networks between students, so is thus anti-social. Jones (1999) found that although two thirds of students taking an online unit found that the approach was better than the 'normal' teaching method, on campus students identified the absence of face to face lectures as one of the problems associated with online teaching. However, this did not seem to be related to the lack of a 'social' aspect of the online work (since on campus students were able to attend traditional tutorials). Rather, these students felt they needed traditional lectures to learn. This highlights the issue of what students are conditioned to believe is the 'best' way to learn; sometimes alternative forms of delivery or learning environments may be resisted initially by students (O'Sullivan and Miron, 2000; Powell, 1981).

This discussion reveals that the bulletin board may offer students additional opportunities to articulate their ideas and discuss issues that arise from readings they undertake, in that the environment is qualitatively different to traditional tutorials. The bulletin board environment is asynchronous, allowing students more time to consider their responses. The discussions are recorded and so can be used as peer derived study tools, and there is a degree of anonymity, which may encourage students to participate more freely. However, these features do not guarantee deep learning will result, nor do they exclude the need for good facilitation by teachers, and the provision of clear guidelines from the outset.

\section{Bulletin boards in practice}

Gender and Organisations is a unit that may be taken by any student at second year or above. When this project was undertaken, the unit had 17 students enrolled, three of whom were graduate students. There were seven men and ten women taking the unit. Three students (one man, two women) did not continue with the unit, so my final group was 14. Eight of the students were full time, although at least three of these worked quite long hours in casual employment outside the University. The other seven were all working full time in paid employment and studying part time. Three of the students were international students. 
I established a bulletin board for the unit, with 11 forums, one being the main forum for general class wide notices and comments. The other ten were labelled with a title relating to each week's reading. The readings were made available in a booklet to be purchased from the University of Canberra Bookshop. The readings were not available online.

Each week two students were to 'lead' the online discussion, by each taking a reading and posting a critical summary of the reading on the bulletin board (within the relevant forum), along with two questions that arose from this reading. Assessment criteria and details on what was meant by a critical summary were included in the unit outline. I printed out the postings and provided comments and a mark and handed them back the following week. The critical summary posting was worth 10 per cent of the final grade.

Each week, the remaining students were each expected to post two separate items in response to the summaries and questions. This 'participation' was worth 1 per cent each week for the 10 weeks of readings.

My involvement was to monitor the discussions, to participate in a facilitator role, and to enable the communications to be as student centred as possible. This meant I kept the length and frequency of my postings to a minimum and I used questions and probes for student responses to keep the discussions focused. Each forum remained open for the duration of the unit, so students could return to previous weeks and revisit the question and answer sessions, or add further comments.

In the first lecture, the first hour was set up so that students had time to meet each other informally, and there were some ice breaking activities. The aim was to help students get to know each other so that they would know with whom they were communicating. The second hour was set aside for an introductory session in a computer laboratory, where students received handouts outlining how to use WebCT's bulletin board and practised logging in and sending messages. At this point we established, as a group, a set of ground rules to ensure a safe and comfortable environment for interaction. This was also the stage when net etiquette was discussed (Berge, 1995). I posted these rules in the main forum. Who to contact for technical problems was also clarified during this session, as was who would be doing which critical summaries for which weeks. 
While there were no face to face tutorials, lectures remained face to face. So, at the beginning of each lecture, I offered students an opportunity to raise any issues or difficulties they had with either the process or the content of the online tutorial sessions. While some in the literature have argued that it is necessary to use the online forum to fix process or content issues (Merron, 1999; Saltmarsh, 2000), I chose to use the bi-modal aspect of the unit to ensure students were coping, and to clarify issues.

\section{Evaluation}

Several techniques were used to investigate if indeed the bulletin boards had been successful in terms of student learning through the discussion of set readings (Alexander and Hedberg, 1991; Beattie, 1991; Laurillard, 1993). These included student evaluations, tracking and content analysis, and peer review and reflection.

\section{Student feedback}

The online tutorial ran for ten weeks, but a student evaluation was undertaken after seven weeks. A questionnaire was distributed during class time. Fourteen responses were received. The questions focused on technical, social, motivational and learning possibilities for students.

On the technical side, 12 out of 14 students found the system easy to access and use (two were neutral on this), while all students said there was sufficient support and feedback from the lecturer and that the objectives of the exercise had been made clear to them at the outset. Of those who attended the introductory session, all agreed that it was useful to them.

Almost all students chose to use the bulletin board to respond to critical summaries, to respond to comments by others, and to make their own postings (two students found the entire online exercise something to be avoided). Half the students spent between 30-40 minutes online per week, the remaining students were spread below and above this time. Two thirds of students made their postings mid-week and the other third at the end of the week. The timing of postings was influenced by other work schedules, computer availability, and meeting the deadline. One third of students waited until other students had posted so that they could respond. 
So what did students feel about their use of online tutorials? Half of the students said the online tutorial sometimes facilitated student-student / student-teacher interaction, while the other half were evenly spread between feeling the online tutorial often or always facilitated studentstudent / student-teacher interaction. Almost all students felt they could often or always express their own opinions and that the forum was a safe and comfortable environment place. One third said they liked the flexibility as to when they could participate, and another third said they liked reading others' opinions and voicing opinions that they might not express in a face to face environment.

Two thirds of students said that they were motivated to undertake the readings and participate in the online tutorial primarily because it was an assessed component of the unit, although almost half of these (that is, one third of all students) also commented that they found the bulletin board a useful tool in terms of keeping up to date with content, maintaining their interest in the subject matter and they felt the exercises encouraged them to express their opinions. It appears then that providing a clearly laid out set of requirements, facilitation by the lecturer and having an assessable aspect to the bulletin board tutorial seems to have encouraged students to participate (Sherry, 1998). For at least one quarter of the students, the flexibility in terms of time was an advantage, and there was evidently a range of times when students chose to make their postings (attend) and how long they chose to be online (participate). These choices were influenced by their other work commitments and their access to a computer.

Two thirds of students said they would not have preferred a traditional tutorial, although most noted they would not want to have the entire unit delivered online, that they liked attending lectures, primarily to have the lecturer reiterate and confirm what they thought they were learning through lectures. There were some concerns: the online discussion did not always flow well, the readings were too long and hard to understand, and two students did not like the 'faceless' nature of the online environment. One quarter of the students had no concerns with the use of bulletin board, while most found it to be a place where they felt safe and comfortable about posting their opinions and they enjoyed being able to read each others comments. There were no significant differences according to non-English speaking background or gender, but given the small sample, I would be hesitant to draw any conclusions from this. 
In summary, in terms of learning, almost all students felt the bulletin board environment encouraged student-student interaction. Around half the students believed it helped them learn because they were able to keep abreast of the issues, their interest was stimulated and they could both express their own opinions and learn from others. However, a small number of students said they found the tasks were too hard and took too long. In the exercises set, students have to read, think and then write a posting for an audience of both peers and teacher. For some, this may take much longer than the preparation required for a traditional tutorial.

\section{Tracking student use of bulletin board}

I used the student tracking function available within WebCT to follow student use of the bulletin board, although I was unable to link this back to the questionnaire to verify student responses, because the questionnaires were anonymously completed. Over the six week period under evaluation, 124 postings were made by students (203 were made over the entire semester). These ranged from 20 word entries through to 200 word entries. Some students were considerably more 'talkative' than others.

During the semester there were ten tutorials in total, so ideally students should have each posted 19 times (one critical summary and 18 responses). Five out of 15 students made at least 19 postings, another third posted between half and three quarters of the required number.

Time spent reading can be measured only by how many postings were read by students. Given that only 203 postings were made during the semester, it appears that 3 students spent some additional time reading, while 5 others read between 134 and 164 postings. Interestingly, not all the prodigious readers were the prodigious posters, highlighting the different activities student take part in within the online environment (listeners and talkers): not unlike the traditional tutorial environment.

To assess the pedagogical value of the learning environment, I have drawn from the assignment work students undertook in order to gain a tutorial participation mark. I undertook a content analysis of the all the messages and summaries posted to the bulletin board tutorial forum over the first seven weeks (Table 1). This method of analysis is a modified version of one used by Salmon (2000). 
Table 1: Summary of postings in Weeks 2-7

\begin{tabular}{|l|c|c|c|c|c|c|}
\hline \multicolumn{1}{|c|}{ Week } & 2 & 3 & 4 & 5 & 6 & 7 \\
\hline No. of postings** & 28 & 18 & 23 & 21 & 15 & 19 \\
\hline $\begin{array}{l}\text { Assessment of 2 } \\
\text { critical summaries }\end{array}$ & None* & $\begin{array}{c}\text { Excel- } \\
\text { lent }\end{array}$ & $\begin{array}{c}\text { Very } \\
\text { good }\end{array}$ & $\begin{array}{c}\text { Very } \\
\text { good }\end{array}$ & Good & $\begin{array}{c}\text { Very } \\
\text { good }\end{array}$ \\
\hline $\begin{array}{l}\text { Questions posed by } \\
\text { critical summaries }\end{array}$ & None* & Yes & Yes & Yes & No & Yes \\
\hline $\begin{array}{l}\text { Response to set } \\
\text { questions }\end{array}$ & None & 9 & 4 & 10 & 0 & 5 \\
\hline $\begin{array}{l}\text { Response to others' } \\
\text { postings }\end{array}$ & 12 & 12 & 11 & 7 & 8 & 5 \\
\hline Independent posting & 8 & 1 & 6 & 1 & 7 & 9 \\
\hline Evidence of reading & 15 & 15 & 17 & 13 & 13 & 11 \\
\hline $\begin{array}{l}\text { Thoughtful and } \\
\text { original posting }\end{array}$ & 16 & All & 15 & All & 10 & 15 \\
\hline $\begin{array}{l}\text { Linking theory to } \\
\text { practice }\end{array}$ & 11 & 9 & 11 & 12 & 7 & 5 \\
\hline
\end{tabular}

* first week of postings, so students were not asked to post critical summaries, but were asked instead to read and post comments they thought were of interest. This constituted a "warm up" exercise.

** excludes the number of postings I made as facilitator. The optimum number of postings would be 28 (one each from the two students posting the critical summaries, and two each from the remaining 13 students who were actively enrolled in the course. I have qualified "enrolled" because three students never attended class and later withdrew).

Looking first at participation, as measured by the number of postings made by students, we see that between 75 per cent and 100 per cent of students made postings in weeks 2, 4 and 5, with around two thirds participating in the remaining weeks. The latter figure reflects Sherry's suggestion that one third of students will always remain silent (Sherry, 1998). However, there are only two students out of the 15 actively enrolled who consistently did not post (13 per cent). The remaining 20 per cent who did not participate in these weeks were not the same students each time (and in at least two of these weeks students were ill and notified me of their inability to make postings).

During the first week online, there was a 100 per cent participation rate. This was the informal session which students could use to discuss the readings but without needing to undertake critical summaries. In only half the responses did it appear that students had read the material in the 
reading booklet, and there was a clear mix of independent and responsive postings. The relatively high number of independent postings may be partly a result of the newness of the environment, with not many of the students knowing each other well at that point. It might also be because no summaries or probing questions were provided, and so students may have felt there was nothing to which to respond. On reflection, this is probably where I needed to step in and set out some introductory thoughts and questions.

Furthermore, it seems that participation does not occur in a vacuum. For example, several of the students found the readings in weeks 3 and 6 either too long or too difficult to understand. This may have deterred students from participating in those particular weeks. Second, another written assignment for the unit was due in Week 6 and so students may have chosen to focus on that (which was worth 25 per cent) and forfeit the 1 per cent they would normally receive for participation online.

In weeks 3 and 5 , about half of the students responded to the questions set by the students who had posted critical summaries, while only a quarter did so in weeks 4 and 7 . However, in all except the last week, at least one third of students also responded to others' postings. When combining these response figures and comparing them with the number of independent postings, it appears that every week there was a considerable amount of interaction between students, and independent postings often stimulated further student response.

Several students noted in their evaluations that sometimes the discussion did not flow, and the lack of face to face contact was problematic. However, online the students were friendly with each other, comfortable about using first names and gently drew attention to the different cultural and gender perspectives. It did not appear to be a 'sterile and impersonal' environment, but was indeed often quite personal, with students sharing their own experiences in ways that reflected arguments made in their readings.

Apart from the first week of online activity (week 2) at least two thirds of students showed evidence of having done some reading. In each week except for week 7 , at least half of the students began to make connections between the theoretical arguments put forward in the literature and the practices they saw occurring in their own organisations and in their personal environment. The reading material often dealt with 'personal' type issues such as the sexual division of unpaid labour in the home; sex role stereotyping of women and men within different cultures and the dimensions of sexual harassment, and sometimes warranted personal 
reflection by students. In some cases, the students engaged with a number of the more complex concepts put forward in the literature and tried to unpack them by relating them to real life practice.

\section{Peer assessment and personal reflection}

One of my peers examined the use of the bulletin board by students and myself, focusing on my role as facilitator, student communications and technical issues. I used a journal to record fortnightly reflections on the time I spent moderating, responding and also on how the dialogue online was progressing.

Prior to the start of the teaching period, I spent much time establishing the bulletin board. This was no doubt because it was the first time I had prepared and run a tutorial in this format. In the initial stages of the unit, the demands on my time for maintaining and monitoring the bulletin were not as high. Navigation seemed straightforward and students were posting in the right place and seemed to adapt quickly to the technicalities of using the bulletin board. In the first two weeks, I logged on twice a day for around five minutes per time. This was adequate to keep in touch with student activity over this introductory period.

As time went on, I found myself spending more time online, marking the critical summaries and following the debates that were developing. However, I would be hesitant to say this would take more time than preparation and participation in a traditional tutorial. What does change is that it is possible to spend much more time online reading student's postings than it is possible to spend in the classroom, where tutorials are limited to the 50 minute timeslot. Therefore, it is important for a facilitator to monitor online time in order to keep it manageable.

Most of my time online was spent reading (which equates with listening in an online sense) and much less time providing input. On average I made three short postings per week, (usually one sentence questions to respond and provoke further thoughts). On reflection, for me this is significantly less time 'talking' compared to traditional tutorials. I wonder if it is a visibility issue. By not being 'seen', students do not seem to look for my approval on their postings. The students seldom responded directly to me, except when I asked a particular question about a reading. In the main they responded to each other's comments. This in itself does not guarantee that learning is taking place, but it certainly seems that this is a strongly student centred and interactive tutorial environment. Furthermore, because students were expected to post questions themselves, and other students provided answers, a sharing between students was taking place, 
which reduced the volume I may otherwise have received. This process encouraged an element of self directed learning to take place.

Berge (1995) argues that long and elaborate individual postings can yield silence in the online environment. While I kept my postings very short, there were two students out of the 15 who regularly posted quite long pieces. This did sometimes yield silence (as measured by a lack of response to those postings), but I also received oral feedback from students who were worried about how much was expected in terms of a posting (in terms of word limit). I think this compares to students who talk a lot in tutorials, to the point where others may feel intimidated about then contributing themselves. To avoid this happening again, I need to ensure the objectives and requirements are more clearly set out, and also work on my skills as a moderator, to ensure students do not feel excluded. This could require me pulling out the main points of the longer student posting and rephrasing them as questions to which students could respond, although this may in turn take more time, the implications of which I would need to investigate in the future. There is also the avenue of privately encouraging 'quiet' students to be more active and 'outspoken' students to hold back a little through the use of email (Berge, 1995).

I had several reasons for selecting the bulletin board for tutorial use. First, we have been encouraged as higher educationalists to be more flexible in our delivery. Second, I was interested in encouraging students to engage more actively with the set readings, through the exercise of posting critical summaries and responses, sharing their thoughts on these readings amongst themselves. Looking at the content analysis of the online tutorial this year, most postings involved substantive comments or questions about the subject matter, and involved some thought and originality. Reflecting on tutorial participation in this unit in previous years, students seemed equally articulate and thoughtful in the online environment this year, and they did seem to be undertaking the set readings.

This, according to Laurillard (1993), is the interactive level, and this is where the student can begin to make the connection between the practice and theory. At least half of the students began to make connections between theoretical ideas and their own experiences of working in organisations. In addition, the bulletin board gave students an additional, alternative forum in which they could discuss and articulate their ideas.

\section{Further reflections and conclusions}

According to O'Sullivan and Miron (2000), facilitation requires more cognitive effort and a wide range of skills and time. It is in this area that I 
still have much to learn, especially in an online environment. For most of my students, participating in an online tutorial was a new experience, just as it was a new experience for me. Most students, while not always outgoing in traditional tutorials, are at least familiar them since that is the means by which smaller group discussion and clarification of ideas takes place. To ensure that students feel confident about using an alternative environment to express their thoughts, I would introduce a number of changes.

I would allow more time and space for introductions online in the early weeks and encourage students to include a more autobiographical type profile, talk about why they are doing the unit and so on. While I got students to do this in the on campus class, I needed to also allow something similar to happen online to help build a sense of community.

Following on from this, I need to work more on my own online communication techniques and provide more feedback and positive reinforcement of good discussant behaviour to help students feel more confident about the effectiveness of their participation (Berge, 1995; Salmon, 2000).

There was some negativity from a few students, although in general almost all the students found the online tutorial good, very good or excellent. The negativity may be due to the change in the way that students were asked to participate, and it did mean it was difficult for students to 'fudge' whether they had done some reading that week. The online bulletin board tutorial required students to take an active role in terms of learning, posing questions themselves, with no requirement for rote learnt response. That there is a resistance to this activity suggests I may need to reevaluate whether too much work is involved, thereby creating anxiety amongst students. I will also examine how I might provide more assistance to help "students to adapt to being challenged to think for themselves" (O'Sullivan and Miron, 2000, p. 6).

In conclusion, based on my project and consequential reflections, I think the bulletin board within WebCT has significant potential to promote interactivity between students and to build a broad sense of community amongst students, in addition to that which occurs in the traditional classroom. This is a project I would like to try again, taking into account the points I have highlighted above. However, just as with any other environment, the bulletin board computer based tutorial setting can be used as a tool for learning only when principles of 'good teaching' are adopted to facilitate the development of independent learners. 


\section{Bibliography}

Adams, D. (1994). Small Group Teaching, CELTS Resource Booklet No. 2, University of Canberra.

Alexander, S. \& Hedberg, J. (1991). Evaluating technology-based learning: Which model? In K. Beattie, C. McNaught and S. Wills (Eds), Interactive Multimedia in University Education: Designing for Change in Teaching and Learning, Amsterdam: Elsevier.

Beattie, K. (1991). How to avoid inadequate evaluation of software for learning. In K Beattie, C. McNaught and S. Wills (Eds), Interactive Multimedia in University Education: Designing for Change in Teaching and Learning, Amsterdam: Elsevier.

Benfield, G. (2000). Teaching on the Web - Exploring the Meanings of Silence. [viewed 18 Oct 2000, verified 13 May 2002] http:/ / ultibase.rmit.edu.au/Articles/online/benfield1.htm

Berge, Z.L. (1995). WebCT Communication: Teaching scenarios and applications. [viewed 10 May 2000, verified 13 May 2002] http: / / www.emoderators.com/moderators / teach_online.html

Brown, S. \& Knight, P. (1994). Assessing Learners in Higher Education. London: Kogan Page.

Forsyth, I. (1996). Teaching and Learning Materials and the Internet. London: Kogan Page.

Gibbs, G. (1992). Active learning in structured lectures. In G. Gibbs \& A. Jenkins (Eds), Teaching Large Classes in Higher Education. London: Kogan Page.

Jones, D. (1999). Solving some problems with university education: Part II. Proceedings AusWeb 1999. [viewed 20 Sep 2000, verified 13 May 2002] http: / / ausweb.scu.edu.au/aw99/ papers/jones / paper.html

Kearsley, G. (1998). A Guide to Online Education. [viewed 24 Jul 2000] http:/ / www.fcae.nova.edu/ kearsley/online.html [verified 13 May 2002 at http: / / home.sprynet.com/ gkearsley/online.htm]

Laurillard, D. (1993). Rethinking University Teaching: A Framework for the Effective Use of Educational Technology. London: Routledge.

Laurillard D. \& Margetson, D. (1997). Introducing a Flexible Learning Methodology: Discussion Paper. Occasional Papers No. 7, Griffith University /GIHE.

MacKnight, C. (1996). Changing Educational Paradigms. Proceedings ASCILITE 96. [viewed 18 Feb 2000, verified 13 May 2002] http: / / www.ascilite.org.au/ conferences/ adelaide96/ papers/macknight.htm

McMurray, D. \& M. Dunlop, M. (2000). The collaborative aspects of online learning: A pilot study. [viewed 15 Sep 2000, verified 13 May 2002] http: / / ultibase.rmit.edu.au/Articles/online/mcmurry1.htm

Merron, J.L. (1999). Managing a Web-based Literature Course for Undergraduates. [viewed 10 May 2000, verified 13 May 2002] http:/ / www.webct.com/service/ ViewContent? contentID $=11751 \&$ community $I D=-1 \&$ categoryID $=-1 \&$ sIndex $=0$ 
O'Sullivan, M. \& Miron, D. (2000). Building a Learning Community Online in a Second Year Computer Science Unit. [viewed 15 Sep 2000, verified 13 May 2002] http:/ / ultibase.rmit.edu.au / Articles / online/ sullivan1.htm

Phillips, R. (1999). Approaches for the Effective Use of Discussion Software. [viewed 18 Feb 2000, not found 13 May 2002] http: / / online.murdoch.edu.au/SCRIPT/unit/scripts / student/serve_home

Powell, J. P. (1981). Reducing teacher control. In D.J. Boud (Ed), Developing Student Autonomy in Learning, London: Kogan Page.

Ramsden, P. (1992). Learning to Teach in Higher Education. London: Routledge.

Reeves, T.C., Laffey, J.M. \& Marlino, M.R. (1997). Using technology as cognitive tools: Research and praxis. Proceedings ASCILITE 97. [verified 13 May 2002] http: / / www.ascilite.org.au/conferences/perth97/ papers/Reeves/Reeves.html

Reid, C. (1999). What happens to democratic space when it is cyber? [viewed $15 \mathrm{Sep}$ 2000, verified 13 May 2002] http:/ / ultibase.rmit.edu.au/Articles/online/reid1.htm

Saltmarsh, D. (2000). Conceptualising an online unit. [viewed 15 Sep 2000, verified 13 May 2002] http: / / ultibase.rmit.edu.au/Articles/online/saltmarsh1.htm

Salmon, G. (2000). E-moderating. The Key to Teaching and Learning Online. London: Kogan Page.

Sherry, L. (1998). The nature and purpose of online discourse: A brief synthesis of current research as related to the Web Project. [viewed 25 Oct 2000, verified 13 May 2002] http: / / www.cudenver.edu/ lsherry / pubs / dialogue.htm

University of Canberra (2000). Approaches to Flexible Learning. [viewed 5 July 2000, restricted access 13 May 2002] http:/ / www.canberra.edu.au/secretariat/internal/flex_learn/pg_plans.html

University of Canberra (2000). Flexible Delivery of Courses and Subjects. [viewed 5 July 2000, restricted access 13 May 2002] http:/ / www.canberra.edu.au/secretariat/internal/flex_learn/delivery.htmlend

University of Canberra (1999). Strategic Plan 1999-2003. [viewed 5 Jul 1999, verified 13 May 2002] http:/ / www.canberra.edu.au/secretariat/strat_plan/intro.html

Author: Dr Jennifer Curtin is a Lecturer in the School of Political and Social Inquiry, Monash University, Clayton Campus, Melbourne, Vic 3800, Australia. Email: Jennifer.Curtin@arts.monash.edu.au. The author would like to thank Coralie McCormack, Peter Donnan, David Moyle, Ruth Foxwell, Penny Collings and reviewers for helpful comments.

\section{Endnotes}

My thanks to Penny Collings for raising this point with me.

During my time as a tutor in two New Zealand Universities, I found this was particularly the case with Maori and Polynesian students, to the point where myself and several colleagues organised separate tutorials for these students, to help them overcome their lack of confidence in speaking about their ideas spontaneously and in public.

ii. This assumes all students have access to an Interne connected computer. Students at the University of Canberra are all issued with online accounts upon enrolment and can 
access computers at various sites on campus, but not all students are Internet connected at home. 